Nature Sustainability, Perspective:

\title{
Before the Next COP: How to stop missing our environmental policy targets
}

Authors: Claude A. Garcia ${ }^{1,2, *}$, Sini Savilaakso ${ }^{3,4}$, René W. Verburg ${ }^{5}$, Natasha Stoudmann ${ }^{6}$, Philip Fernbach ${ }^{7}$, Steven A. Sloman ${ }^{8}$, Garry D. Peterson ${ }^{9}$, Miguel B. Araújo ${ }^{10,11}$, Jean-François Bastin $^{12}$, Laurence Boutinot ${ }^{2}$, Hélène Dessard $^{2}$, Anne Dray $^{1}$, Scott Francisco $^{13}$, Jaboury Ghazoul $^{14,15}$, Laurène Feintrenie ${ }^{2,16,17}$, Fritz Kleinschroth ${ }^{14}$, Babak Naimi ${ }^{18}$, Ivan P. Novotny ${ }^{1}$, Johan Oszwald $^{19}$, Stephan A. Pietsch ${ }^{20,21}$, Fabien Quétier ${ }^{22}$, Brian E. Robinson ${ }^{23}$, Marieke Sassen $^{24,25}$, Plinio Sist ${ }^{2}$, Terry Sunderland ${ }^{26}$, Cédric Vermeulen ${ }^{27}$, Lucienne Wilmée ${ }^{28,29}$, Sarah J. Wilson $^{30}$, Francisco Zorondo Rodríguez ${ }^{31}$, Patrick O. Waeber ${ }^{1, *}$

\section{Affiliations:}

${ }^{1}$ Forest Management and Development, Department of Environmental Systems Science, Institute of Terrestrial Ecosystems, ETH Zürich; Zürich, Switzerland.

${ }^{2}$ CIRAD, UPR Forêts et Sociétés; Montpellier, France.

${ }^{3}$ Liljus ltd; London, United Kingdom.

${ }^{4}$ Department of Forest Sciences, University of Helsinki; Helsinki, Finland.

${ }^{5}$ Copernicus Institute of Sustainable Development, Utrecht University; Utrecht, The Netherlands.

${ }^{6}$ School of Technology, Environments and Design, University of Tasmania; Hobart, Australia.

${ }^{7}$ Leeds School of Business, University of Colorado; Boulder, USA.

${ }^{8}$ Cognitive, Linguistic, \& Psychological Sciences, Brown University; Providence, USA.

${ }^{9}$ Stockholm Resilience Centre; Stockholm University; Stockholm, Sweden. 
${ }^{10}$ Department of Biogeography and Global Change, National Museum of Natural Sciences, CSIC; Madrid, Spain.

${ }^{11 ، R u i ~ N a b e i r o ’ ~ B i o d i v e r s i t y ~ C h a i r, ~ M E D ~ I n s t i t u t e, ~ U n i v e r s i t y ~ o f ~ E ́ v o r a ; ~ E ́ v o r a, ~ P o r t u g a l . ~}$

${ }^{12}$ CAVELab Computational and Applied Vegetation Ecology, Department of Applied Ecology and Environmental Biology, Faculty of Bioscience Engineering, Ghent University; Ghent, Belgium.

${ }^{13}$ Pilot Projects Design Collective; Montreal, Canada and New York, USA.

${ }^{14}$ Ecosystems Management. Department of Environmental Systems Science, Institute of

Terrestrial Ecosystems, ETH Zürich; Zürich, Switzerland.

${ }^{15}$ Centre for Sustainable Forests and Landscapes, School of GeoSciences, University of Edinburgh; Edinburgh, Scotland.

${ }^{16}$ CATIE, División de Investigación para el Desarrollo Verde e Inclusivo, Turrialba, Costa-Rica.

${ }^{17}$ ICRAF Latin America office; Lima, Perú.

${ }^{18}$ Department of Geosciences and Geography, University of Helsinki; Helsinki, Finland.

${ }^{19}$ Département de Géographie, Université de Rennes; Rennes, France.

${ }^{20}$ IIASA-International Institute of Applied Systems Analysis, ASA-Advanced System Analysis Program; Laxenburg, Austria.

${ }^{21}$ BOKU-University of Natural Resources and Life Science, Department of Forest and Soil Sciences, Institute of Silviculture; Vienna, Austria.

${ }^{22}$ Biotope; Mèze, France.

${ }^{23}$ Department of Geography, McGill University; Montréal, Canada.

${ }^{24}$ UN Environment Programme World Conservation Monitoring Centre (UNEP-WCMC; Cambridge, United Kingdom. 
${ }^{25}$ Plant Production Systems Group, Wageningen University \& Research; Wageningen, The Netherlands.

${ }^{26}$ Faculty of Forestry, University of British Columbia; Vancouver, Canada.

${ }^{27}$ Université de Liège, Faculté de Gembloux Agro-Bio Tech, FORIL, Unité Gestion Ressources Forestières, Laboratoire de Foresterie tropicale; Gembloux, Belgium.

${ }^{28}$ World Resources Institute Africa, Madagascar Program; Antananarivo, Madagascar.

${ }^{29}$ Madagascar Research \& Conservation Program, Missouri Botanical Garden; Antananarivo, Madagascar.

${ }^{30}$ PARTNERS Reforestation Network, Department of Ecology and Evolutionary Sciences, University of Connecticut; Storrs, USA.

${ }^{31}$ Universidad Santiago de Chile, Departamento Gestión Agraria Facultad Tecnológica, Santiago de Chile, Chile.

*Correspondence to: Claude Garcia claude.garcia@usys.ethz.ch, Patrick Waeber patrick.waeber@usys.ethz.ch

One-Sentence Summary: To improve the efficiency of environmental policy-making, incorporate human decisions and power relations into the decision-making process.

\section{Abstract}

While the scientific community has focused on documenting environmental degradation and developing scenarios that help identify the operational margins for system Earth, less attention has been given to the mental models of decision-makers that underpin environmental policies. We suggest that global efforts to stop deforestation and biodiversity loss are failing in part due to a 
critical blind spot in the analysis-human agency. To address this weakness, we propose to formulate mental models and translate them into strategy games. This will increase the representation of agency in scenario development and create spaces for deliberation between different worldviews. We claim that personal transformation can be achieved through transparent democratic dialogues that identify, challenge, and respond to the human and social limitations inherent to decision-making and we present empirical examples that validate that claim. Their transformation through gaming gives decision-makers access to the experience of consciousness: “what is it like being a stakeholder?". Such experience will help to break free of established norms in science and political processes.

Keywords: Agency, Transition, Cognition, Land-use change, Games, Democracy

\section{Main Text:}

\section{Today's limited range of policy options}

Policy changes are the result of complex decision-making processes that involve difficult choices, power struggles, expediency, availability of resources, perception of public support, and much more. Policies can also be viewed as a product of the interaction between policy-makers' mental models and the narratives they adopt (Fig. 1). Narratives are stories. The narratives we are referring to here are about the changes one wants to see either happen or avoided ${ }^{1}$. A mental model is the functional but incomplete representation a person has of how (a part of) the world works. It is based on a person's knowledge, experience, values, beliefs, aspirations and sympathies ${ }^{2}$. Different mental models will generate different policy outcomes from the same scenario or narrative. Policy responses therefore change when either (i) the narratives adopted by policy-makers change, or when (ii) their mental models change. 
Scientific panels and science/policy interfaces tend to focus on the former, developing more complicated models to improve the narratives and present them in a compelling yet accessible form. The latter, changing mental models, is best achieved when working directly with policy-makers. Here we analyze that second pathway for transformation to improve the efficiency of environmental-policy-making in the context of the post-2020 agenda.
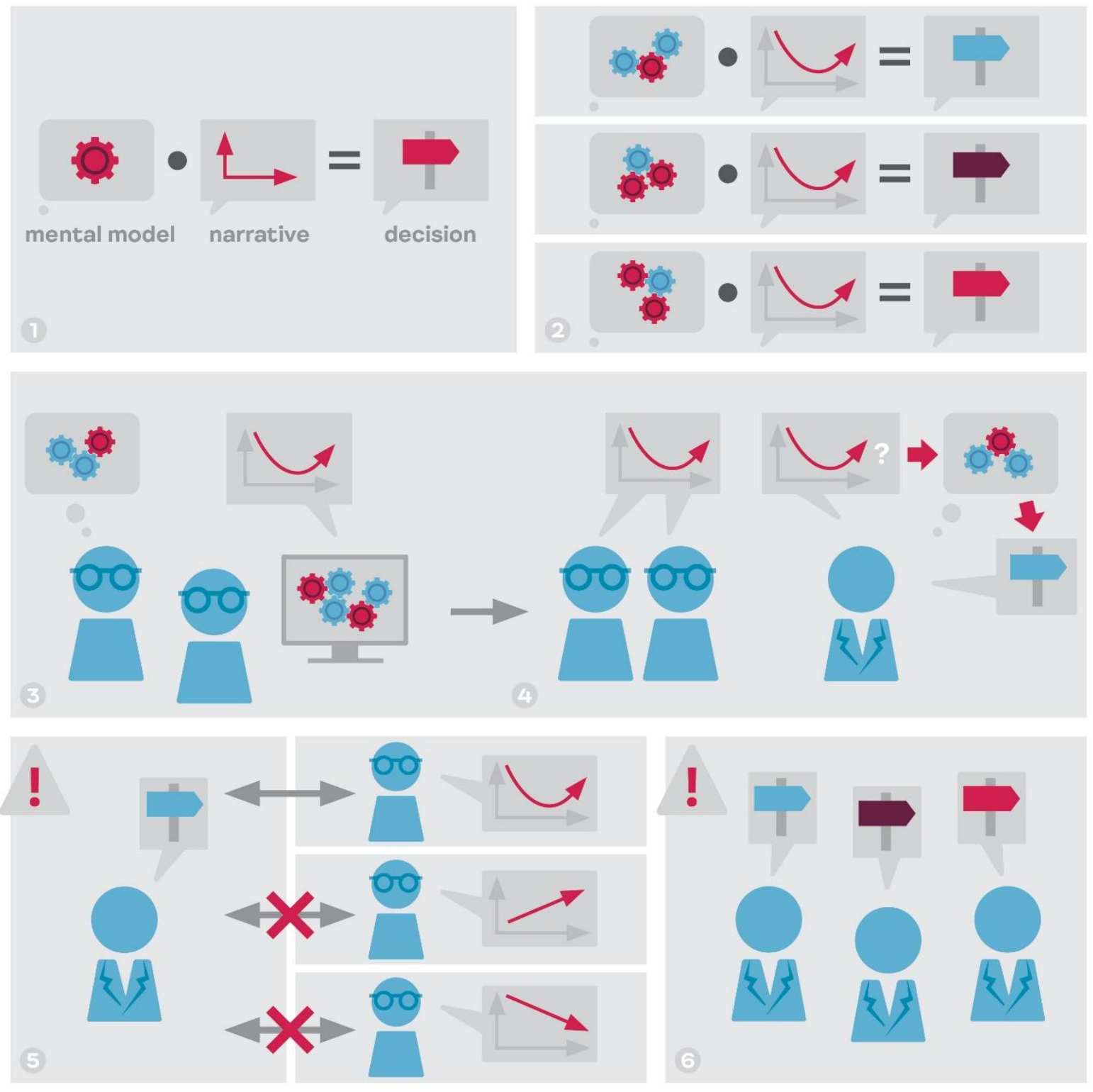
Fig. 1: Narratives and mental models are the two levers of efficient decision-making. (1) Decisions result from the combination of narratives and mental models. Everyone has a mental model (cogs). Different colors represent different fields of knowledge. The more cogs the more complicated the model. (2) Different mental models will result in different policy outcomes from the same scenario or narrative. (3) Experts develop models_external, explicit, often in silico-representing System Earth. These models produce output scenarios. (4) Experts present these scenarios as narratives to policy-makers. Some policy-makers adopt the narratives-while developing their own interpretation based on their own mental models — to produce a policy outcome statement. Disclaimer: This heuristic is a highly simplified conceptualization of how science and policy interfaces happen. (5) Policy-makers selectively hear and listen to experts based on prior priming and already established narratives. Experts work on problems framed by the sociopolitical context they are embedded in and selectively receive funding to look at specific issues. (6) External factors, political lines or economic interests, public support, media opinions are internalized in the mental models of decisionmakers as well as the power relations between them will affect the final outcome of policy negotiations ${ }^{3,4}$.

The world's governments did not reach most of the international social and environmental targets set for 2020. None of the 20 Aichi Biodiversity Targets have been fully achieved, and only six have been partially accomplished $^{5-7}$. Current trajectories continue diverging from goals and pledges ${ }^{5,8}$. This is a problem involving every single human, albeit with vastly different degrees of responsibility ${ }^{9}$. Some of us are unaware of the problem. Many of us actively resist change. Others do not care, and a small but growing number are concerned and trying to push for change. Collectively, humans have proven to be unwilling, unprepared, or unable to change $e^{9,10}$.

The post-2020 global biodiversity framework of the Convention on Biological Diversity (CBD) is being developed and new ambitious targets, goals, actions and strategies for biodiversity and sustainability are being proposed $^{11}$. These will affect governments' actions for decades to come ${ }^{12}$. The responses, ambitions and policy decisions that are being drafted for the post-2020 agenda are, inter alia, informed by scenarios outlined by 
Integrated Assessment Models (IAMs) developed by scientists and economists combining different strands of knowledge $\mathrm{e}^{13,14}$.

Current IAMs have been built to explore policy options; besides being heavily constrained by data and models ${ }^{15}$, they are also constrained by the values they integrate. To address this constraint, the Nature Futures Framework recently developed by the Intergovernmental Science-Policy Platform on Biodiversity and Ecosystem Services (IPBES), proposes a heuristic framework that accommodates a plurality of perspectives on what is desirable for the future ${ }^{16}$. Along with not considering values, IAMs fall short in representing how humans behave and interact $^{17}$. Scenarios derived from IAMs are therefore restricted to the exploration of "what ifs?", i.e., target-seeking scenarios in which transformations do not result from emergent behavior of the decision-making processes represented in the model but are imposed ex machina ${ }^{18}$. These limitations make it difficult to link IAMs to decisionmakers. Ignoring or misrepresenting human agency in these models limits the range of options that are contemplated and opens doors to systemic stalling and undesired surprises as people will develop adaptive responses and coping strategies to whatever action plan is proposed ${ }^{19}$.

\section{Changing narratives by incorporating human decision-making into modeling}

Translating models into participatory strategy games allows diverse values and agency to be incorporated into models, expanding the range of the options that can be contemplated. Land-use and land-cover change models can be the basis for strategy games that incorporate human decisionmaking. In such games, critical decisions over land-use changes, access to credit or setting of boundaries for example, are made by humans, while the outcomes of their decisions will depend on the interaction between their decisions, other players' decisions, and the limits and rules of the 
game $^{20-22}$. There is a trend in gaming to create more controlled experiment-like big data games $^{23}$. We propose here to go in a different, people-centered direction. We need experimentation with new types of sciencepolicy engagement that have the potential to reach transformation through breaking free of established norms ${ }^{24}$.

A game being played, with facilitation and debriefing, is a constructive process of cocreation that produces a common understanding among the players of how the system works $^{25}$. On the basis of this common understanding, players can then engage in a decentralized collective and distributed process of seeking new solutions through play. The gameboard and tokens represent the landscape and its components. Players represent stakeholders with power to shape the board and adapt to changing conditions. Game rules represent system processes. A game session is the equivalent of a simulation run - a narrative about how things could unfold. It is possible to identify winners and losers and to revise strategies. These games lack precision and generality, but they link causal mechanisms and causal effects ${ }^{25}$ and can serve as boundary objects that bridge science and policy ${ }^{26}$.

Participatory games such as the ones we outline here have been used and developed for more than 40 years in fields such as system dynamics, adaptive environmental management science and participatory action $\operatorname{research}^{25,27}$. An example is the climate game C-ROADS. Though direct impact is difficult to assess, people changed the way they negotiated based on $\mathrm{it}^{28}$. Relying on decentralized problem solving, participatory games offer an alternative to expert-driven top-down prescriptive approaches that have proven limited in their ability to manage complexity and uncertainty. They have the potential to significantly change policymaking process and outcomes, if played by keystone actors ${ }^{29}$, i.e., people vested with power and responsibility having a disproportionate ability to steer the direction 
of the system. Participatory games represent an untapped potential to address environmental issues ${ }^{30}$. Yet, despite their capacity to integrate a plurality of perspectives and to support collective action preparing stakeholders to better cope with surprises, these games have yet to be successfully deployed at the scale of international decision-making and achieve macro-scale impact. Why? Because they have not been played by the right players. The games can be played by anyone. However, unless the participants are vested with power to shape norms and policies, the lessons drawn by participants are not translated into changes of the normative landscape and therefore fail to register at the global scale, notwithstanding the scalability of the model ${ }^{28}$. Farmers playing cannot change prices at the farm gate. Students playing cannot change laws. Interns playing cannot change corporate policies.

\section{Policy-makers changing their mental}

\section{models}

Placing participatory games at the center of the science-policy interface has great potential to support transformative change. If IAMs provide the classic model outputs such as shared socioeconomic pathways (SSPs), participatory games allow policy-makers to personally engage with the model and the development of scenarios, complementing the SSPs. Such an approach requires that decision-makers agree to engage in the role playing that the games propose, taking on the role of the different actors within the models of the systems they intend to transform. The models can then be the subject of debate from within, their limitations identified, and assumptions revealed through use, play, and dialogue $^{21}$. Decision-makers engaging in such processes have the chance to develop future scenarios and counterfactualspropositions that are contrary to facts. Counterfactual thought occurs when a person considers a change to the state of affairs and 
then assesses the consequences of that change $^{31}$. A critical distinction with other forms of engagement is that counterfactual information is not provided to the participants. Instead they develop counterfactuals by themselves, on the basis of the game they are discovering as they play. This spurs the challenging of one's own assumptions and cognitive biases ${ }^{32}$. More importantly, it provides the direct experience that has the potential to shape the mental models of the decision-makers.

Participatory games have been used at large scales to connect science and policy, in sectors such as health and defense $\mathrm{e}^{23,33}$. Below we give three examples from biodiversity conservation and then discuss how such games have been used in other domains.

In 2017, negotiators of the Regional Working Group on High Conservation Values (HCVRWG) of the Forest Stewardship Council (FSC) supported the development of a set of indicators related to the identification and management of Intact Forest Landscapes
(IFLs) in the Congo Basin. The participants of the workshop played MineSet, a game that represents regional landscape dynamics for Central Africa and the interactions between extractive industry projects, logging, agribusiness, infrastructure development, population growth, forest dynamics, market fluctuations and regional policies (S1). With the support of game masters and facilitators, they analyzed their game session and established connections between the issues at stake and their experience during the game. This collective understanding enabled them to find an agreement after three days of play, discussion, and negotiation, resolving a gridlock that had lasted for more than two years $^{21,34}$. According to the convenor of that meeting, the director of the FSC Program for the Congo Basin, the game and the facilitation "(..) allowed members of the HCV-RWG, coming from different cultures, countries and with a very heterogeneous education background, to acquire, in only two days, the same level of understanding 
regarding IFLs concept, and how each management decision could impact the landscape, its resilience and forest-dwell[ing communities]. From the beginning of the internal HCV-RWG discussions, no consensus seemed to be achievable across the different interests (...). Thanks to [games and facilitation], the $\mathrm{HCV}-\mathrm{RWG}$ reached a consensus (...) This first solution is a major step globally to move, in the short-term, towards an internationally acknowledged way to manage IFLs in Congo Basin Forests." (S2).

Another example of large-scale participatory gaming is the Oil Palm Adaptive Landscape (OPAL) project. Between 2015 and 2021, some of the authors designed landscape and supply chain games to understand and support decision-making processes in the oil palm supply chain, in Cameroon, Indonesia and Colombia. In 2016, members of the InterMinisterial Committee on Palm Oil, responsible for regulating palm oil pricing in Cameroon played one such game,
CoPalCam, designed with smallholder farmers and professionals from the industry to understand the bottlenecks in the production at the country level (S3). The game sessions brought together participants from the Ministry of Agriculture and Rural Development, six smallholder cooperatives, representatives of the agro-industry and civil society organizations. Scenarios around price fixing and farmers cooperation were at play. This dialogue contributed to the relaunch of discussions on the national strategy for sustainable palm oil, which had been on hold since 2014. After this session, the game was used by the government to support dialogues with smallholders on the creation of cooperatives_one of the most promising strategies that emerged from the game. Following this, smallholders close to the plantations of the Société Camerounaise de Palmeraies (SOCAPALM) in Dibombari initiated the creation of a cooperative on the basis of the lessons they drew from the game. 
Others renegotiated contracts with the industrial mills ${ }^{35}$.

In 2019/20, civil servants from the Indonesian Ministry of Agriculture revised the rules for the Indonesian Sustainable Palm

Oil certification scheme on the basis of the discussions that followed game sessions held with the Oil Palm Adaptive Landscape (OPAL) research team. The game used was co-designed and validated with small-scale oil palm growers, villagers, local government officials, NGO and private companies in East Kalimantan and then brought to the Ministry offices to support the critical analysis of the contemplated policies. Using the lessons from the game and debriefing, local government and private companies are currently rediscussing scenarios for sustainable palm oil plantations.

Large-scale gaming with high-level decisionmakers has also been used in pandemic preparedness. Pandemic simulations like Event 201 (simulating a novel Coronavirus pandemic, played in October 2019 by scientists, government officials and business leaders, in New York City) have been running since the early 2000s, taking cues from war-games used by the military to stress-test health systems. The participants of Event 201 were shocked by the simulation outcome; the game experience helped identify gaps in governments' responses to the outbreak ${ }^{36}$. The game did not contemplate the possibility of an adversarial federal administration, but there is no reason why such actors cannot be embedded into game scenarios or, even, participate as potentially antagonistic players.

In all cases, the value and impacts of game sessions depends on the nature of the participants. Participatory games enable a dialogue between different scales of decision-making, from the village council to the Ministry office and beyond, to the General Assembly of the United Nations and along value chains from producers to consumers $^{30}$. They serve to convey how different participants perceive the system 
better than other forms of scientific communication $^{25}$. These games will not dissolve existing power structures and asymmetries, nor the inequalities they create. Instead they reveal them, as they highlight the winners and losers of the strategies that are considered ${ }^{25}$. They reveal and challenge assumptions. They do not show the solutions but place people in the situation to develop them. They thus serve to identify innovative strategies and solutions outside of policy options considered at present, with the potential to overcome current systemic lockins.

\section{How to make games work?}

For a particular game session to trigger transformation, three events must happen, sequentially, one enabling the others ${ }^{37}$. First, the session must happen. Second, the session must transform the mental models of the participants. Third, the participants must act upon these learnings. Failure in any of these three steps precludes impact.
1-Calling for the game

Leadership. The first condition for a session to be organized is for a convenor to step forward. The person or institution calling for the meeting, inviting the participants and proposing the use of the game as support for dialogue, is critical for the success of the process. The difficulty to fulfill this condition explains why there have been not more sessions at higher levels of decision-making.

Participation. The second condition is for players to respond to the call of the convenor. What can bring participants to the table? There are a variety of reasons that can trigger the decision to join. Participants will join because they can, because they want, and/or because they must. They can respond to the convenor, they can be attracted by the other participants, by the venue or by whatever they expect will happen. Three actionable levers deserve mention to attract participants. (1) Signaling. Bystanders will be convinced to join when participants signal and broadcast the quality of the experience. In management 
sciences, this is the best solution for the socalled "empty restaurant syndrome"38.

Interest. Negative environmental externalities are essentially byproducts of our choices; few people have negative attitudes towards the environment and the destruction of forest is not the objective pursued ${ }^{9}$. If participants think participating will help them do better in whatever matters to them, they will join. (3) Conformity. Recruiting players for the initial sessions can be difficult. If people expect others will participate and they prefer to act like most others, the conditions are met for a social tipping point that will make further sessions easier to organize ${ }^{10,22}$.

\section{2-A transformative experience}

Once the session begins, a different set of conditions is required for participants to change their mental models.

Validity. The first condition is that the game must represent the constraints and opportunities stakeholders face in the field. The games we describe are models of the reality as we think it is, a description of what we think a landscape is and how it works. For the game to be useful, it needs to share the logical structure of the system it represents $\left(\right.$ sensu Wittgenstein ${ }^{39}$ ). The rules of the game must be congruent with the causal effectsthe structure of cause and effects and the magnitude of the responses_- known from the system. We ensure this during the design phase by validating the game with the stakeholders themselves. The game is valid when these early players say "this is my reality" ${ }^{\prime 4}$. Once this is achieved, everyone playing the game will experience what it is like to be one of the other stakeholders represented in the game.

Failure to achieve validity in the eyes of the players can result either in the loss of credibility of the session-it is effectively a child's game_-or maybe more dangerously, it can lead participants to ill-founded and potentially counter-productive conclusions. We avoid these pitfalls by teaching participants to maintain a critical distance from the game, recognizing it is a model with 
all the limitations this entails. Participants also get to learn the rules of the game in order to play. In so doing they are able to judge whether or not these rules correspond to their understanding of the system. Discrepancies highlight the different perceptions between these players and the stakeholders engaged in the design of the game.

Facilitation. Skilled facilitation is the second condition to ensure the game and the ensuing discussions are fruitful. The process of confronting one's own cognitive limitations and wrong assumptions is source of frustration and discomfort ${ }^{41}$. Additionally, participants that have a self-perception of high expertise on the topic touched upon by the game have a more closed-minded attitude, in addition to maybe feel belittled $^{42,43}$. Facilitation can help transform these difficult personal experiences into opportunities for learning and self-reflection. Another danger to avoid is that power relations invade the game session. Power is represented in the model, and is an essential element of the player's strategies. There must be room to have a discussion about its origins, distribution and limits ${ }^{44,45}$. The facilitator can ensure that powerful players do not curtail the discussion. Deciding strategically who will play what role can contribute to the success of the discussion.

Engagement. The attitude of the players is the third condition that drives the success of the game itself. Irrespective of the reason why the participants joined the sessions to begin with, the game can only exist for as long as the players are engaged with it and decide to play.

Transformational experience. This is probably the most challenging part to convey. Information is insufficient to generate change $\mathrm{e}^{46}$. We resist changing values, but we adjust our expectations and our mental models of the world on a regular basis, whenever we experience surprise ${ }^{47}$. Players undergo emotional responses when playing - surprises, frustration and triumph, anger, and joy, all can be experienced 
through a well-designed and well-run game $\operatorname{session}^{48}$. The personal, direct, emotional experience of the impacts of our decisions transforms the things we know into things we care for. This is how and when the participants update their mental models.

Time. Finally, the last ingredient is time. Time to process the information is one of the limiting factors of bounded rationality ${ }^{49}$. Here, in view of the complexity of the systems and the possibilities explored by the game, players need to devote sufficient time to learn the rules, explore different strategies and consider counter-plays and possible setbacks. Failure to spend enough time playing can lead to missed opportunitiesnot finding the right strategies — and to hasty decisions_ overlooking hidden pitfalls.

\section{3-After the game}

After the participants walk out of the session, they remain with the full responsibility of their future choices. The experience has given (a) different meaning to things they probably already knew. The session has served to reveal winners and losers, costs and opportunities. Their future choices will be better informed, though not necessarily different. Participants will make different choices if they can, if they want, and/or if they must. For participants to enact change, conveners and facilitators need to mind the following:

Self-agency. Participants will resist if they feel the process is an exercise in manipulation $^{50}$. Trust in the model, transparency in the design process, and willingness of the convenor to revise assumptions and to act upon the lessons learnt are defining elements that will contribute to the willingness of the participants to follow through and implement change.

Empowerment. Players need to be empowered to make decisions. This can stem from their position in society, their mandates, their charisma or personal considerations. Empowerment can also stem from the venue where the sessions were convened, or the 
policy process to which they are connected. If the players are constrained by their hierarchies or social norms, no change will happen. These considerations need to be integrated in the design of the game sessions $^{22}$.

Self-efficacy. Empowerment can also come from within. Lacking the core belief that one can make a difference by one's actions ${ }^{51}$ contributes to apathy, inaction, displacement behaviour, resignation or worse, adhesion to the current pathway ${ }^{9}$. Finding promising strategies directly contributes here. A powerful way to promote this is to compare game sessions, showing how others have solved the same problem-as a way to collectively identify better solutions ${ }^{52}$.

\section{An application for global sustainability}

Let us apply this approach to an ongoing, global environmental wicked problem whose resolution has eluded us over the last 30 years: the global forest transition ${ }^{21}$. Can we stop deforestation and biodiversity erosion, bring back trees and forests on Earth to preindustrial levels? Our understanding of the drivers of deforestation and degradation ${ }^{53,54}$ allow us to formulate a narrative for this transition (Fig. 2). Forest cover globally will increase when forest landscape restoration increases, deforestation reduces and halts and forest degradation reduces and halts. Forest landscape restoration will increase when forest landscape restoration projects are better targeted, trees planted only where it makes sense and forest growth is allowed to happen. Deforestation will reduce when infrastructure development over forests reduces and stops, and when agriculture expansion over forests reduces and stops. Forest degradation will reduce when timber, fuelwood, charcoal and other non-timber forest products extraction reduces or stops, and when fire management improves. 


\section{Forest cover increases globally.}

\section{Biodiversity erosion is reduced to pre-industrial levels.}

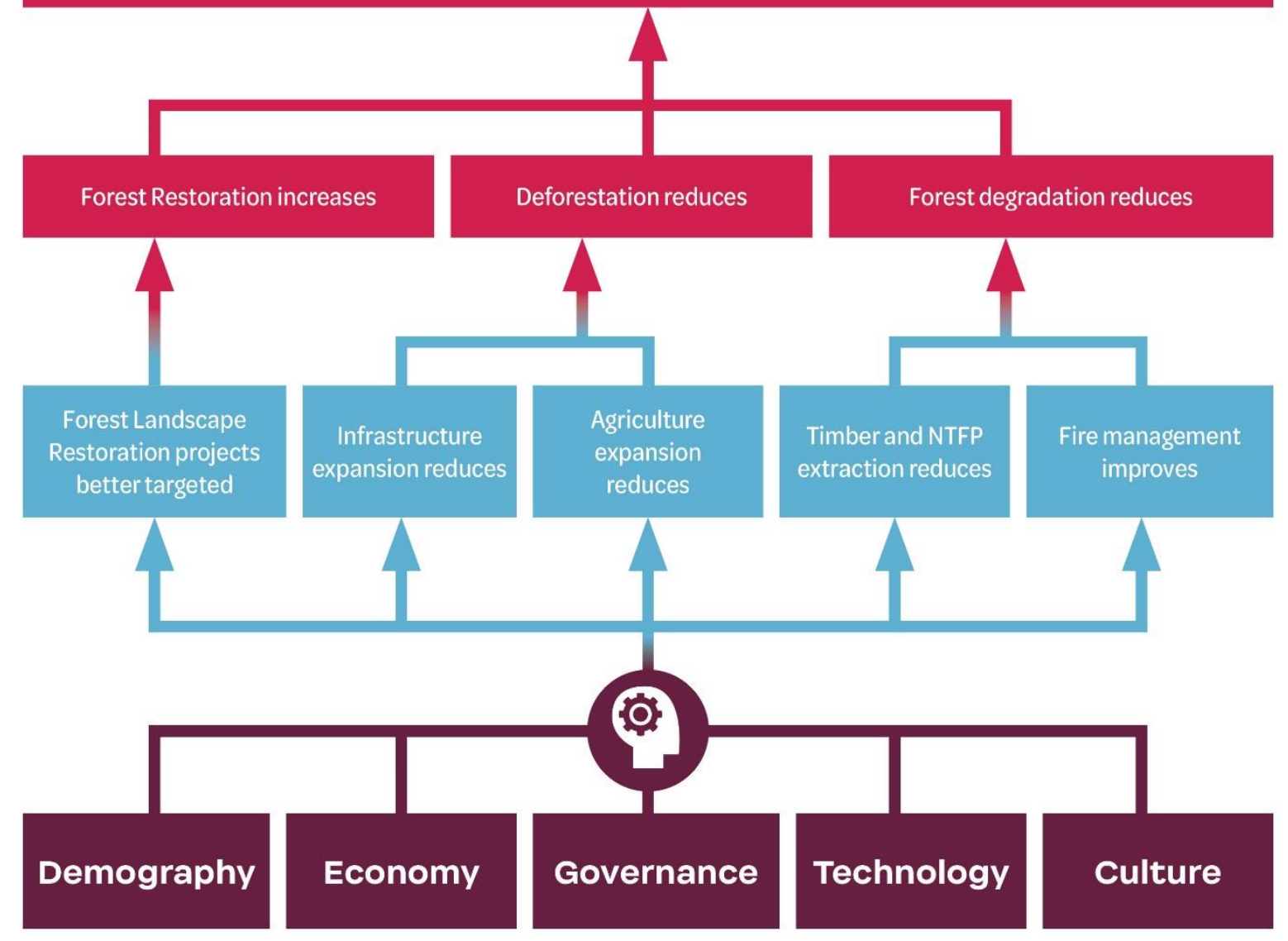

Fig. 2: How and why the global forest transition will happen. Change in forest cover and biodiversity is under the influence of human activities that can be traced to five types of underlying drivers. These drivers condition the transformation of practices leading to the global forest transition. Both drivers and practices rest on the decisions made by humans, therefore on the combination of narratives and mental models.

This narrative (Fig. 2) complete as it is, says nothing about how to operate the transition.
What is missing is the consideration of the mental models - the functional but 
incomplete representations people have of the of their own capabilities, the capabilities of others, and the natural and physical processes at play at the time of making the decision $^{9,21,55}$. For the transition to happen, the context under which decisions are made must change. However, this condition needs to be met for everyone directly involved in shaping landscapes. For the millions of farmers, for the agro-industries, for the mining, road and infrastructure development firms to change their practices, the contexts in which they operate must change ${ }^{56}$. For this to happen, donors and finance institutions, governments, NGOs, local communities, administrations, all have to change the way they make decisions and the basis on which their decisions are made. This sounds impossible to achieve. Indeed, we do not think the forest transition can be triggered through a centralized process. Instead, we can rely on distributed collective intelligence ${ }^{57}$. Since the transformation we seek is systemic, all five families of drivers
(Fig. 2) need to be involved—social workers to address the lever of demography and population movements, corporations, banking and finance administrations for the levers of economy, academia, start-ups and incubators for technological innovations, elected representatives, political leaders, the judiciary to press on the governance levers, and finally artists, faith leaders, intellectuals and story tellers to lean on the lever of cultural change (Fig. 2). Every one of us, in our respective field, can play a role in this transformation ${ }^{9}$. The transition can develop through a decentralized, distributed process (Fig. 3). It all begins with one session where high-profile participants experience the transformation of their mental model and signal to others the validity of the approach. Enabled by this demonstration, early influential adopters begin testing, adopting and promoting the method within their networks, institutions and constituencies. Percolating through the hierarchical structures, stakeholders end up making 
decisions on the basis of redesigned incentive

structures.

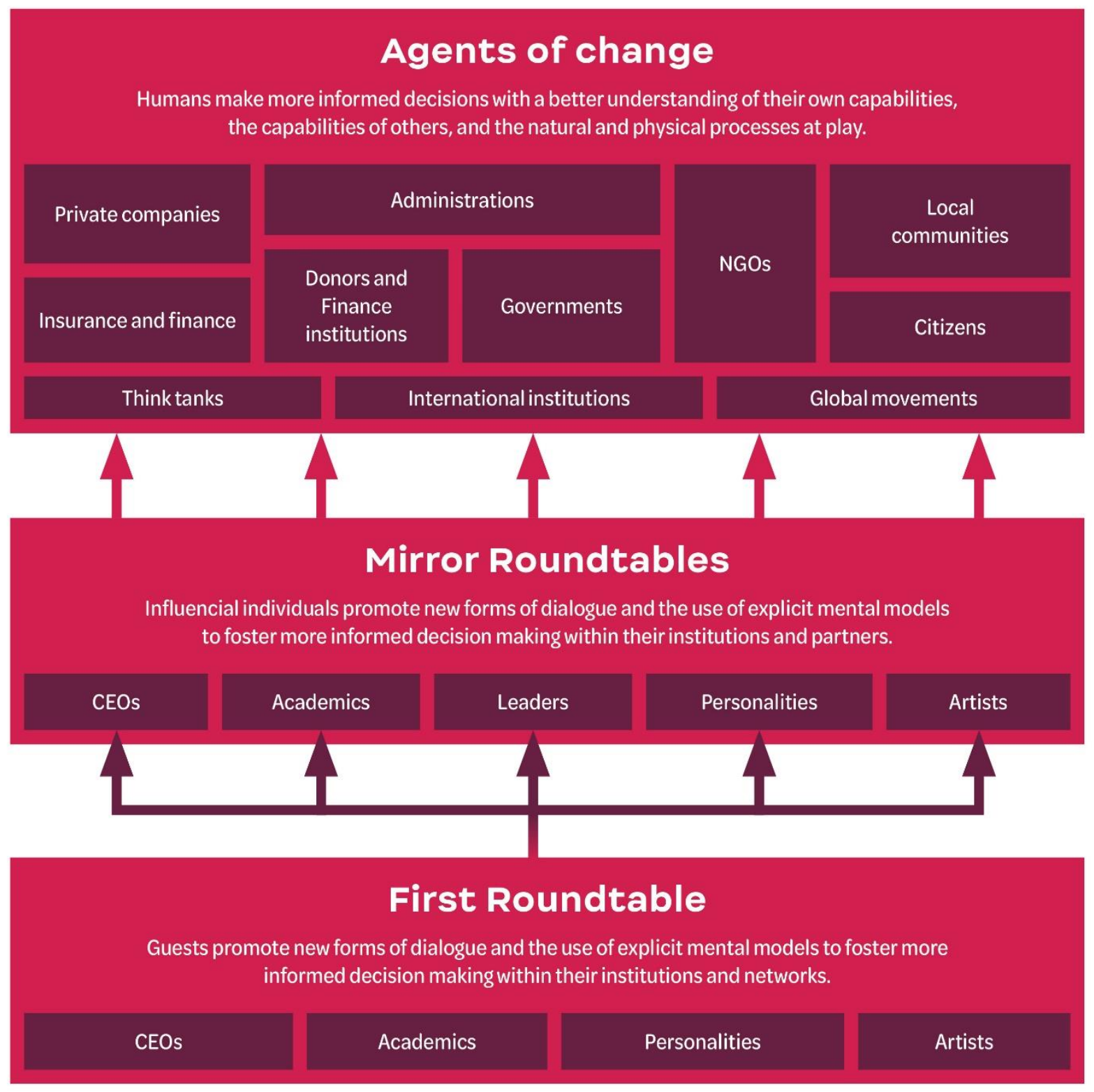

Fig. 3: Designing landscape change. We propose that, to transform the system that results in deforestation, we can modify the decisions made by people. This can happen through a decentralized, distributed process in three stages: (1) High profile influencers are invited to discover the method to promote the new forms of dialogue and the use of games to foster more informed decisions within their institutions and networks. (2) Encouraged by this early example, influential individuals promote the use of these tools within their institutions and constituencies. (3) Stakeholders and 
agents of change make more informed decisions in their respective arenas, on the basis of modified incentive structures redesigned on the basis of dialogues and games.

\section{Reforming decision-making processes}

Global assessments have become a key focus

of global environmental decision-making.

Producing such assessments is a useful way

to summarize the state of knowledge and

support evidence-based decision-making.

However, there are other, maybe more

fruitful ways to engage decision-makers such

as the one we outline here. These alternative

ways should be more widely adopted in

international scientific panels of

intergovernmental bodies like IPCC and IPBES.

We suggest there are reforms that could make existing processes more engaging and relevant, as well as transformations that could substantially transform global decision processes. Scenario development at IPBES and IPCC should not just involve successful

IAMs but also better include human agency, thereby increasing the relevance of the narratives and policy options proposed. In the lead up to CBD COP15 and other conferences of the parties, we call on national decision-makers to engage in interactive workshops to find potential new solution pathways, which can then be brought to international negotiations.

Reform oriented measures would include bringing lessons from science communication and engagement into scientific assessments. How? Executive summaries convey narratives. They do not change mental models. Games and other interactive products can be designed as part of assessments to provide a means to interactively explore combined impacts of possible policies ${ }^{28}$. Integrating these into assessments is a way to convey both the narratives and underlying models. This would require that game creation and modelling teams are integrated to the assessments. Such teams could be supported 
as part of the assessment process or supported by funders but tied to assessments.

The transformation of the Earth's ecological system can begin by reforming how decisions are made. Transforming target-seeking COP summits towards action-delivering $\mathrm{COPs}$ through dynamic engagement in the negotiations is a way forward. This requires breaking away from established policymaking norms. Courage is required from policy-makers to participate, and support is needed from the public.

\section{Conclusion}

As long as human agency remains external to the international science-policy interfaces and the policy decision-making processes, it will be difficult to develop robust policies that take into account the complexities of social and ecological system transformations. The odds are that we will miss the intended environmental targets again. However, the approach we have described may help design more effective post-2020 sustainability frameworks.
How is what we propose different from any other form of science-policy interface? The answer is structured collective intelligence. We are proposing to replace hidden, unformulated and opaque decision-making processes happening in the minds of decision makers, with collective, explicit and transparent problem exploration and solution identification processes. We offer to redesign the way decision makers come to a decision, through a pragmatic, value agnostic yet inclusive method to develop narratives and update mental models. We will change the choices we make when we change the way we make choices.

\section{References and Notes}

1. Jarva, V. Introduction to narrative for futures studies. Journal of Futures Studies 18, 5-26 (2014).

2. Moon, K. et al. Mental models for conservation research and practice. Conserv. Lett. 12, e12642 (2019). https://doi.org/10.1111/conl.12642

3. Burstein, P. The impact of public opinion on public policy: A review and an agenda. Polit. Res. Q. 56, 29 40 (2003). 
https://doi.org/10.1177\%2F1065912 90305600103

4. Lamb, W.F. \& Minx, J.C. The political economy of national climate policy: Architectures of constraint and a typology of countries. Res. Soc. Sci. 64, 101429 (2020). https://doi.org/10.1016/j.erss.2020.1 01429

5. Díaz, S. et al. Pervasive humandriven decline of life on Earth points to the need for transformative change. Science 366, eaax3100 (2019). https://doi.org/10.1126/science.aax3 100

6. Díaz, S. et al. Summary for policymakers of the global assessment report on biodiversity and ecosystem services of the Intergovernmental Science-Policy Platform on Biodiversity and Ecosystem Services," (IPBES Secretariat, 2019).

7. Global biodiversity outlook 5 (Secretariat of the Convention on Biological Diversity, 2020).

8. Leclère, D. et al. Bending the curve of terrestrial biodiversity needs an integrated strategy. Nature 585, 551556 (2020). https://doi.org/10.1038/s41586-0202705-y

9. Waeber, P.O. et al. Choices we make in times of crisis. Sustainability 13, 3578 (2021). https://doi.org/10.3390/su13063578

10. Nyborg, K. et al. Social norms as solutions. Science 354, 42-43 (2016). https://doi.org/10.1126/science.aaf83 17

11. Xu, H.et al. Ensuring effective implementation of the post-2020 global biodiversity targets. Nat. Ecol. Evol. (2021).

https://doi.org/10.1038/s41559-020-

01375-y

12. Díaz, S. et al. Set ambitious goals for biodiversity and sustainability. Science 370, 411-413 (2020). https://doi.org/10.1126/science.abe1 530

13. Van Soest, H.L. et al. Analysing interactions among sustainable development goals with integrated assessment models. Global Transitions 1, 210-225 (2019). https://doi.org/10.1016/j.glt.2019.10. 004

14. McLaren, D. \& Markusson, N. The co-evolution of technological promises, modelling, policies and climate change targets. Nat. Clim. Chang. 10, 392-397 (2020). https://doi.org/10.1038/s41558-0200740-1

15. Araújo, M.B. et al. Standards for distribution models in biodiversity assessments. Sci. Adv. 5, eaat 4858 (2019). https://doi.org/10.1126/sciadv.aat485 8

16. Pereira, L.M. et al. Developing multiscale and integrative naturepeople scenarios using the Nature Futures Framework. People and Nature 2, 1172-1195 (2020).

17. Preston, B.L. et al. Scale and the representation of human agency in the modeling of agroecosystems. Curr. Opin. Environ. Sustain. 14, 239-249 (2015). https://doi.org/10.1016/j.cosust.2015. 05.010

18. Otto, I.M. et al. Human agency in the Anthropocene. Ecol. Econ. 167, 106463 (2020). 
https://doi.org/10.1016/j.ecolecon.20 19.106463

19. Saltelli, A. et al. Five ways to ensure that models serve society: a manifesto. Nature 582, 482-484 (2020).

20. Daw, T.M. et al. Evaluating taboo trade-offs in ecosystems services and human well-being. Proc. Natl. Acad. Sci. U.S.A. 112, 6949-6954 (2015). https://doi.org/10.1073/pnas. 141490 0112

21. Garcia C.A. et al. The global forest transition as a human affair. One Earth 2, 417-428 (2020). https://doi.org/10.1016/j.oneear.2020 .05 .002

22. Garcia, C.A. et al. Coffee, farmers, and trees-shifting rights accelerates changing landscapes. Forests 11, 480 (2020). https://doi.org/10.3390/f11040480

23. Reddie, A.W. et al. Next-generation wargames. Science 362, 1362-1364 (2018). https://doi.org/10.1126/science.aav2 135

24. Lahsen, M. \& Turnhout, E. How norms, needs, and power in science obstruct transformations towards sustainability. Environ. Res. Lett. 16, 025008 (2021).

https://doi.org/10.1088/17489326/abdcf0

25. Redpath, S.M. et al. Games as tools to address conservation conflicts. Trends Ecol. Evol. 33, 415-426 (2018). https://doi.org/10.1016/j.tree.2018.03 .005

26. van Voorn, G.A.K. et al. A checklist for model credibility, salience, and legitimacy to improve information transfer in environmental policy assessments. Environ. Model. Softw. 83, 224-236 (2016). http://dx.doi.org/10.1016/j.envsoft.2 016.06.003

27. Fujitani, M. et al. Participatory adaptive management leads to environmental learning outcomes extending beyond the sphere of science. Sci. Adv. 3, e1602516 (2017). https://doi.org/10.1126/sciadv.16025 16

28. Rooney-Varga, J. N. et al. Combining role-play with interactive simulation to motivate informed climate action: Evidence from the World Climate simulation. PloS ONE 13, e0202877 (2018).

29. H. Österblom, H. et al. Transnational corporations as 'keystone actors' in marine ecosystems. PloS ONE 10, e0127533 (2015).

https://doi.org/10.1371/journal.pone. 0202877

30. Speelman, E. N. et al. Serious gaming as a tool to facilitate inclusive business; a review of untapped potential. Curr. Opin. Environ. Sustain. 41, 31-37 (2019).

31. Roese, N. J. \& Epstude, K.. The functional theory of counterfactual thinking: New evidence, new challenges, new insights. In Advances in experimental social psychology (Vol. 56, pp. 1-79). Academic Press, 2017.

32. Fernbach, P.M. et al. Political extremism is supported by an illusion of understanding. Psychol. Sci. 24, 939-946 (2013). https://doi.org/10.1177\%2F0956797 612464058

33. Lofgren, E.T. \& Fefferman, N. H. The untapped potential of virtual 
game worlds to shed light on real world epidemics. Lancet Infect. 7, 625-629 (2007). https://doi.org/10.1016/S14733099(07)70212-8

34. Kleinschroth, F., Garcia, C. \& Ghazoul, J. Reconciling certification and intact forest landscape conservation. Ambio 48, 153-159 (2019). https://doi.org/10.1007/s13280-0181063-6

35. Kamto, M. et al. Using role-play to explore strategies for improving palm oil production and sustainability in Cameroon. ETFRN NEWS 139 (2019).

36. Maxmen, A. \& Tollefson, J. Two decades of pandemic war games failed to account for Donald Trump. Nature 584, 26-29 (2020). https://doi.org/10.1038/d41586-02002277-6

37. Marengo, L. \& Zeppini, P. The arrival of the new. J. Evol. Econ. 26, 171-194 (2016). https://doi.org/10.1007/s00191-0150438-0

38. Kremer, M. \& Debo, L. Inferring quality from wait time. Manag. Sci. 62, 3023-3038 (2016). https://doi.org/10.1287/mnsc.2015.2 264

39. Wittgenstein, L. Tractatus logicophilosophicus. English edition first published in 1922. Routledge, 2019.

40. Fauvelle, E. \& Garcia, C.

AgriForEst: un jeu pour élaborer des scénarios sur un terroir villageois d'Afrique Centrale. VertigO 18 (2018). https://doi.org/10.4000/vertigo.2324 5
41. Festinger, L. A theory of cognitive dissonance (Vol. 2). Stanford university press, 1962.

42. Wood, S.L., \& Lynch Jr, J.G. Prior knowledge and complacency in new product learning. J. Consum. Res. 29, 416-426 (2002). https://doi.org/10.1086/344425

43. Ottati, V. et al. When selfperceptions of expertise increase closed-minded cognition: The earned dogmatism effect. J. Exp. Soc. Psychol. 61, 131-138 (2015). https://doi.org/10.1016/j.jesp.2015.0 8.003

44. Mermet, L. (2011). Strategic environmental management analysis: addressing the blind spots of collaborative approaches. IDDRI, Collection Idées pour le débat, 5 .

45. Barnaud, C. et al. Power asymmetries in companion modelling processes. In Companion Modelling (pp. 127-153). Springer, Dordrecht, 2014.

46. Ferris, F.D., von Gunten, C.F. \& Emanuel, L.L. Knowledge: insufficient for change. J. Palliat. Med. 4, 145-147 (2001).

47. Castelfranchi, C. Mind as an anticipatory device: For a theory of expectations. In International Symposium on Brain, Vision, and Artificial Intelligence; De Gregorio, M., Di Maio, V., Frucci, M., Musio, C., Eds.; Springer:

Berlin/Heidelberg, Germany, 2005; pp. 258-276.

48. Garcia, C., Dray, A. \& Waeber, P. Learning begins when the game is over: using games to embrace complexity in natural resources management. GAIA-Ecological Perspectives for Science and Society 
25, 289-291 (2016).

https://doi.org/10.14512/gaia.25.4.13

49. Broadbent, D.E. Perception and communication. New York:

Pergamon Press, 1958.

50. Arnstein, S.R. A ladder of citizen participation. J. Am. Plann. Assoc. 35, 216-224 (1969).

51. Bandura, A. Toward a psychology of human agency. Perspect. Psychol.

Sci. 1, 164-180 (2006). https://doi.org/10.1111\%2Fj.17456916.2006.00011.x

52. Le Page, C. et al. Exploring how knowledge and communication influence natural resources management with ReHab. Simulation \& Gaming 47, 257-284 (2016). https://doi.org/10.1177\%2F1046878 116632900

53. Geist, H.J. \& Lambin, E.F. Proximate causes and underlying driving forces of tropical deforestation; tropical forests are disappearing as the result of many pressures, both local and regional, acting in various combinations in different geographical locations. BioScience 52, 143-150 (2002). https://doi.org/10.1641/00063568(2002)052[0143:PCAUDF]2.0. $\mathrm{CO} ; 2$

54. Meyfroidt, P., et al. Middle-range theories of land system change. Glob. Environ. Change, 53, 52-67 (2018).

55. Grantham, H.S. et al. Anthropogenic modification of forests means only $40 \%$ of remaining forests have high ecosystem integrity. Nat. Commun. 11, 5978 (2020). https://doi.org/10.1038/s41467-02019493-3
56. Kleinschroth, F. \& Healey, J.R. Impacts of logging roads on tropical forests. Biotropica 49, 620-635 (2017). https://doi.org/10.1111/btp.12462

57. Pea, R.D. Practices of distributed intelligence and designs for education. Gavriel Salomon. Distributed cognitions Psychological and educational considerations, Cambridge University Press, pp.4787, 1993.

Acknowledgments: We are thankful to Sylvain Mazas for designing the illustration and the Forest Stewardship Council Congo Basin Office, its former director Mathieu Auger-Schwartzenberg and his colleagues Olivia Rickenbach and William Lawyer for entrusting us with the facilitation of the Regional Working Group on High Conservation Values (HCV-RWG) session in Brazzaville in 2017. The empirical examples given here stem from the work of the CoForTips project (ANR-12EBID-0002) funded by the ERA-NET BiodivERsA, with the national funders ANR, BELSPO and FWF, as part of the 2012 call for research proposals, and the 
OPAL project financed by the Swiss National Science Foundation (r4dEcosystems) grant no. 152019. The MineSet model was developed by the CoForSet project, funded by the FRB 2013 call for research proposals "Scenarios of Biodiversity for Subsaharan Africa", with support by the FFEM. MineSet was tested with Tropenbos International at their offices in Wageningen. We thank Hans Vellema, TBI Programme coordinator, Rosalien Jezeer Junior programme coordinator and Erika Speelman, WUR, for their support.

Funding: This research received no external funding.

\section{Author contributions: $\mathrm{CAG}$ and POW}

developed the initial draft. SS, RWV, SAS, PF, GDP, MBA contributed improving the draft, all other authors contributed to revising the manuscript. The manuscript builds on the discussions previously held by the authors in the development of two papers, Garcia et al 2020 (\#21) and Waeber et al 2020 (\#9).

Competing interests: Authors declare that they have no competing interests.

\section{Supplementary Materials}

S1 - Timelapse of a MineSet session (Tropenbos)

S2 - Letter FSC

S3 - CoPalCam Movie ( Cameroon) 